\section{Gray Mold in and Quality of Strawberry Fruit following Postharvest Heat Treatment}

\author{
José M. García, Cayetano Aguilera, and Antonia M. Jiménez \\ Consejo Superior de Investigaciones Cientificas, Instituto de la Grasa, Avda. \\ Padre García Tejero 4, 41012 Seville, Spain
}

Additional index words. Fragaria $\times$ ananassa, Botrytis cinerea, firmness, fruit quality

Abstract. Strawberries (Fragaria $\times$ ananassa Duch. 'Tudla') were inoculated with gray mold conidia (Botrytis cinerea Pers.) and were subjected to postharvest heat treatment by dipping in water at various temperatures for 15 min. Heat treatment delayed Botrytis proliferation, but using dips at $\mathbf{2 4 8 C}$ caused fruit to soften and develop an atypical pink pigmentation. Fruit treated at 44 or $46 \mathrm{C}$ showed the best retention of firmness and maintained initial quality, developing neither an off-color nor an off-flavor.

Botrytis cinerea is a ubiquitous, fungal, plant pathogen that causes economic losses in a wide range of fruit, vegetables, and ornamentals in the field and during transport and storage. Strawberry fruit are highly susceptible to its action. Control of Botrytis during storage can be achieved by physical and chemical methods. Increasing $\mathrm{CO}_{2}$ concentrations and decreasing temperatures were effective in reducing the mycelial development of this fungus (Brown, 1922; Reyes and Smith, 1986). However, high $\mathrm{CO}_{2}$ concentrations could cause an off-flavor in strawberries (Ke et al., 1994 Li and Kader, 1989). Although significantly reducing Botrytis growth, using low temperatures alone is not $100 \%$ effective in Botrytis control. Chemical methods of controlling decay also have been studied (Smith and Worthington, 1965), but there is increased concern among consumers about the potentially harmful health effects of chemical treatments (Klein and Lurie, 1991). Postharvest heat treatments are nonpolluting physical procedures for insect disinfestation and disease control in fresh horticultural products. They were used in the 1920s (Fawcett, 1922), but with the development of effective fungicides and insecticides with persistent pesticidal activity, interest in them waned. Nevertheless, with the increase in the chemical treatmen restrictions, studies on applying heat treatment to fresh produce have revived. Recent contributions in this field have been summarized (Barkai-Golan and Phillips, 1991; Coates and Johnson, 1993; Couey, 1989; Klein and

Received for publication 17 Apr. 1995. Accepted for publication 25 Oct. 1995. This research was supported by Proyecto de Investigación ALI920393 from "Plan Nacional de Ciencia y Tecnología de Alimentos" and by Asociación Onubense de Productores y Exportadores de Fresa. We thank M.C. Martínez-Peláez for her excellent technical assistance. The cost of publishing this paper was defrayed in part by the payment of page charges. Under postal regulations, this paper therefore must be hereby marked advertisement solely to indicate this fact.
'Tudla' strawberries (Fragaria $\times$ ananassa) were harvested early in the morning and transported to the laboratory where undamaged fruit at the same ripening stage $(80 \%$ of the skin red) was selected and distributed randomly among seven treatments of 300 fruit $(\approx 5 \mathrm{~kg})$ each. A $20-\mu 1$ droplet containing 1.94 $\times 10^{5}$ conidia of $B$. cinerea $/ \mathrm{ml}$ water was placed on the surface of each fruit. Three 100strawberry replicates for each treatment were inoculated. The conidia were obtained by washing mycelia from a pure culture grown on potato dextrose agar (PDA) with a $1 \%$ Triton$\mathrm{X} 100$ solution. After filtering and centrifuging at $6500 \mathrm{~g}$ for $5 \mathrm{~min}$, the pellet was resuspended in water. The conidia were counted using a Bürker camera (Superior Gmbh, BadMergentheim, Germany), and the final concentration was adjusted by dilution. One hour after the inoculation, six of the seven groups of inoculated strawberries were submerged for $15 \mathrm{~min}$ at 40, 42, 44, 46, 48, and 50C in thermostatically controlled water baths for heat treatments. Afterwards, the fruit were dried, using a dry air stream at 50C for $5 \mathrm{~min}$, and were placed in a room at $18 \mathrm{C}$. Using an air stream for drying the fruit after the hot-water dip only affected the internal temperature of the fruit slightly because the energy supplied was used to evaporate the water located on the fruit's surface. The seventh group was placed directly in the $18 \mathrm{C}$ room without heat treatment. At the same time, further control was provided by another seven groups with the same number of noninoculated strawberries, which were subjected to the same treatments. The experiment was performed in two consecutive seasons under the same conditions.

The number of fruit in the various treatments with visible mycelial growth of Botrytis was monitored daily for 4 days. Ten noninoculated healthy fruit were taken at random from

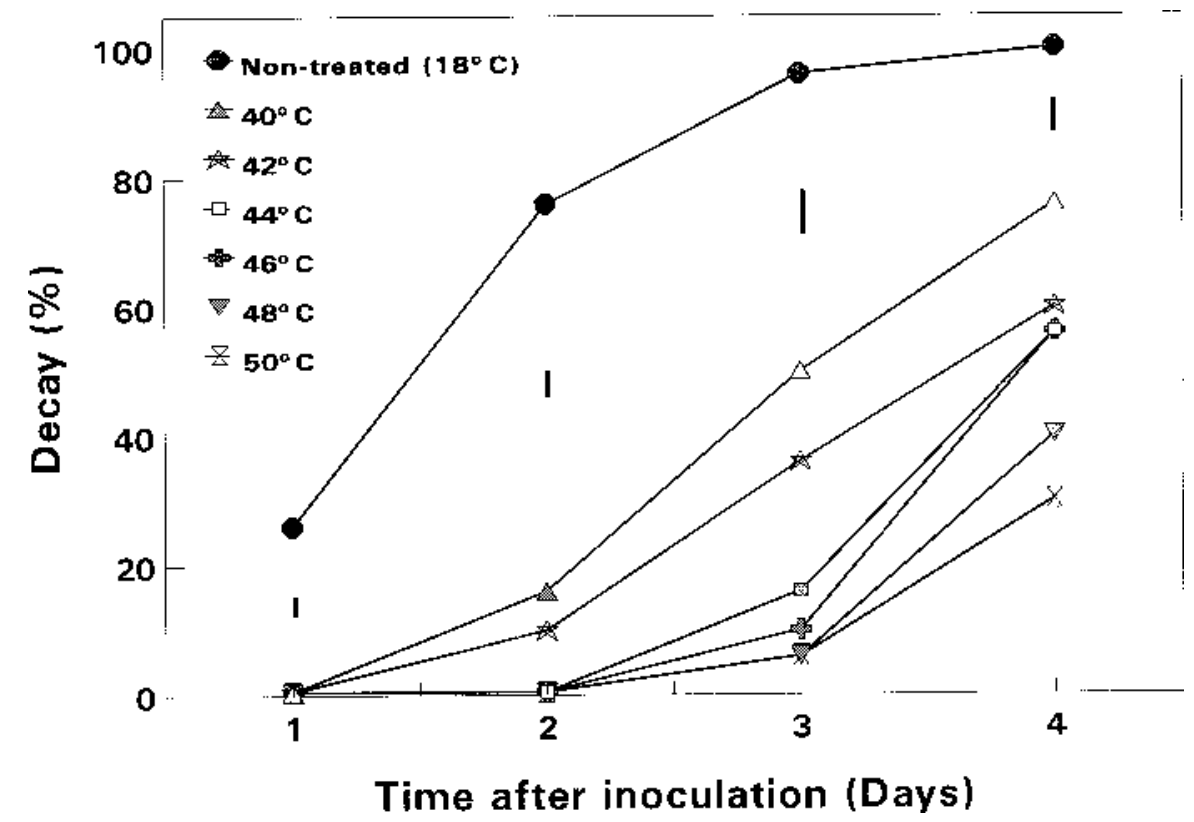

Fig. 1. Decay in strawberry fruit inoculated with Botrytis cinerea conidia and later treated with 15-min water dips at various temperatures. Vertical bar represents least significant difference at $P \leq 0.05$. 
each treatment daily for measuring fruit firmness using a densimeter (model 3300; Zwick Gmbh \& Co., Ulm, Germany) with a 5-mm disk. (The force required to depress the disk $2.4 \mathrm{~mm}$ into the fruit was determined. Data are expressed in newton per square centimeter of probe surface). Samples of 24 noninoculated healthy fruit were taken daily at the same hour from each treatment and were tested organoleptically in a sun-illuminated room by an analytical panel of 12 tasters using the simplified procedure of multiple comparisons (Mahoney et al., 1957). Nonheated fruit were used as a reference sample. The possible occurrence of off-flavors or off-colors as a consequence of heat treatment was especially examined.

Analysis of variance was performed on all the data. Least significant difference at $P \leq$ 0.05 was used to establish differences among the means obtained in the treatments.

\section{Results and Discussion}

For inoculated fruit, the extent of fungal growth was inversely related to the temperature used in the heat treatment (Fig. 1). Thus, fruit treated at 50C needed 4 days to achieve the same percentage of mycelial development as the nontreated fruit on the first day after inoculation. The fruit treated at 40 and $42 \mathrm{C}$ were intermediate in behavior with significantly less mycelial development than nontreated fruit but more than the other heattreated fruit. Three days after inoculation, there was no statistically significant difference in mycelial growth between fruit treated at 44 or $46 \mathrm{C}$ and between fruit treated at 48 or $50 \mathrm{C}$. Four days after inoculation, decay of 48 and $50 \mathrm{C}$ fruit was significantly $(P \leq 0.05)$ less than in fruit from all other treatments. As was the case with low temperature and high $\mathrm{CO}_{2}$ concentrations (Agar et al., 1990), hot-water dips significantly delayed gray mold development but did not prevent it.

Heat treatments also were effective in controlling postharvest decay in the noninoculated fruit (Fig. 2). After 3 days at 18C, $>15 \%$ of the nontreated fruit had decayed, while $<5 \%$ of the heated fruit showed decay. Treatments at 40 and $48 \mathrm{C}$ were less effective after 4 days at $18 \mathrm{C}$. However, berries treated at $44 \mathrm{C}$ had a lower, but not statistically significant, incidence of decay at 4 days than the other berries. These data agree with the decay control obtained by Couey and Follstad (1966) using moist air at the same temperature.

Treatments at 48 or $50 \mathrm{C}$ injured fruit quality. Strawberry fruit treated at these temperatures showed a significantly greater loss of fruit firmness than fruit subjected to other treatments (Fig. 3). This softening was accompanied by the development of an atypical pink pigmentation on the fruit (data not shown) like that of boiled strawberries, which made the fruit unmarketable. Fruit treated at 44 or $46 \mathrm{C}$ retained firmness best, maintaining $\approx 90 \%$ of the initial value even 4 days after heat treatment. Nontreated fruit and fruit heated at 40 and $42 \mathrm{C}$ showed an intermediate behavior, losing a mean of $25 \%$ of the initial value of

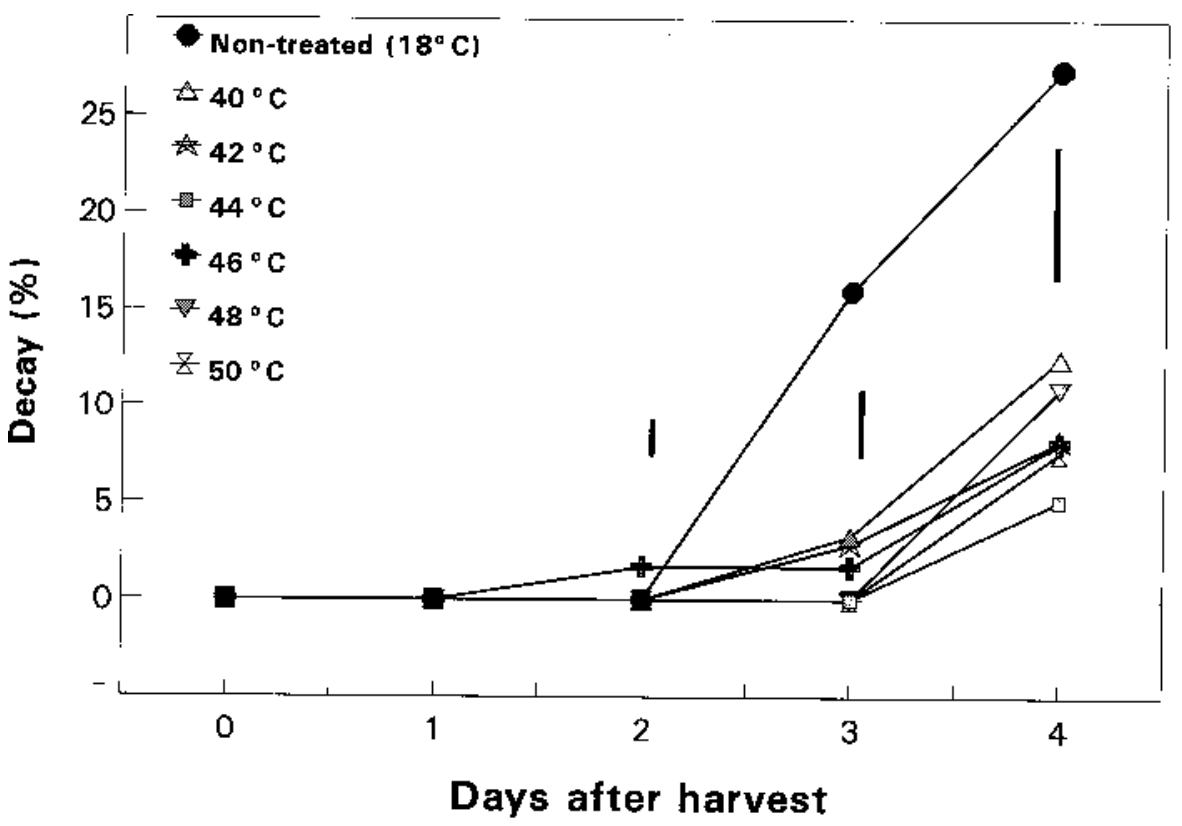

Fig. 2. Decay in noninoculated strawberry fruit treated with 15 -min water dips at various temperatures. Vertical bar represents least significant difference at $P \leq 0.05$.

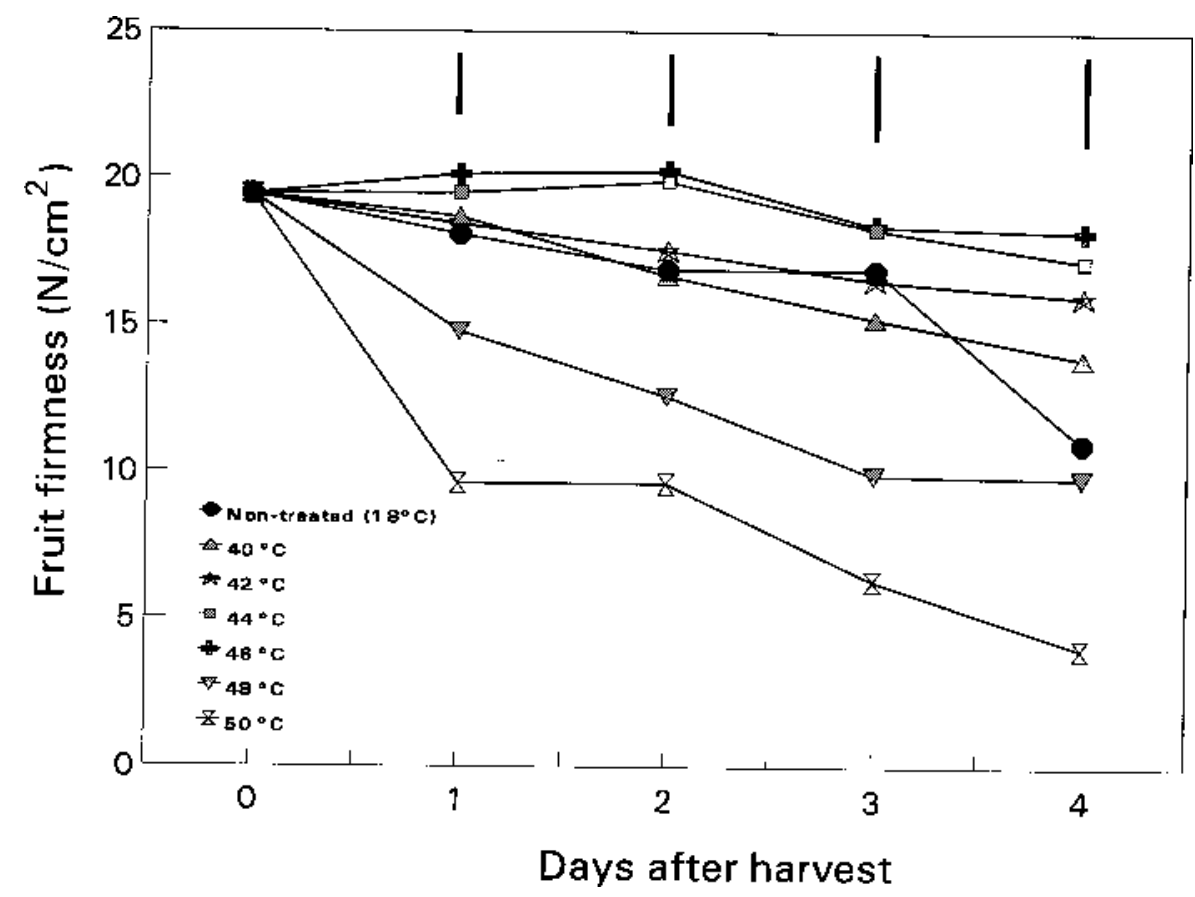

Fig. 3. Decrease in firmness (newtons per square centimeter) of strawberry fruit treated with 15 -min water dips at various temperatures. Vertical bar represents least significant difference at $P \leq 0.05$.

fruit firmness. Biggs et al. (1988), Eaks (1978), and Klein and Lurie (1991) found firmness to be retained after heating of various fruit.

Sensory analysis did not find any negative effect of heat treatments at $<48 \mathrm{C}$ on fruit quality. These fruit maintained their initial quality for 4 days after heat treatment, developing neither the atypical pink nor an offflavor. The appearance and the softening of fruit treated at $\geq 48 \mathrm{C}$ gave them a repulsive flavor, and they were rejected.

Immersion in water at 44 or $46 \mathrm{C}$ allowed the best control of Botrytis development without affecting sensory quality of fruit. Heat treatments could be especially suitable in prac- tice for strawberries with a foreseeable high postharvest decay, such as fruit harvested after rain. Studies on the compatibility of these heat treatments with storage at low temperature and high $\mathrm{CO}_{2}$ are needed.

\section{Literature Cited}

Agar, T., J.M. García, U. Miedtke, and J. Streif. 1990. Effect of high $\mathrm{CO}_{2}$ and low $\mathrm{O}_{2}$ concentrations on the growth of Botrytis cinerea at different temperatures. Gartenbauwissenschaft 55:219-222.

Akamine, E.K. and T. Arisumi. 1953. Control and postharvest storage decay of fruits of papaya (Carica papaya L.) with special reference to the 
effect of hot water. Proc. Amer. Soc. Hort. Sci. 61:270-274.

Barkai-Golan, R. and D.J. Phillips. 1991. Postharvest heat treatment of fresh fruits and vegetables for decay control. Plant Dis. 75:1085-1089.

Biggs, M.S., W.R. Woodson, and A.K. Handa. 1988. Biochemical basis of high temperature inhibition of ethylene biosynthesis in ripening tomato fruits. Physiol. Plant. 72:572-578.

Brown, W. 1922. On the germination and growth of fungi at various temperatures and in various concentrations of oxygen and carbon dioxide. Ann. Bot. 47:257-283.

Coates, L.M. and G.I. Johnson. 1993. Effective disease control in heat-disinfested fruit. Postharvest News \& Info. 4:35N-40N.

Couey, H.M. 1989. Heat treatment for control of postharvest diseases and insect pests of fruits. HortScience 24:198-202.

Couey, H.M. and M.N. Follstad. 1966. Heat pasteurization for control of postharvest decay in fresh strawberries. Phytopathology 56:1345-1347.

Eaks, I. 1978. Ripening respiration and ethylene production of 'Haas' avocado fruit at 20 to $40^{\circ} \mathrm{C}$. J. Amer. Soc. Hort. Sci. 103:576-578.

Fawcett, H.S. 1922. Packing house control of brown rot. California Citrogr. 7:232-254.

Ke, D., L. Zhou, and A.A. Kader. 1994. Mode of oxygen and carbon dioxide action on strawberry ester biosynthesis. J. Amer. Soc. Hort. Sci. 119:971-975.

Klein, J.D. and S. Lurie. 1991. Postharvest heat treatment and fruit quality. Postharvest News \& Info. 2:15-19.

Li, Ch. and A.A. Kader. 1989. Residual effects of controlled atmospheres on postharvest physiology and quality of strawberries. J. Amer. Hort. Sci. 114:629-634.

Mahoney, C.H., H.L. Stier, and E.A. Crosby. 1957. Evaluating flavor differences in canned foods. II. Fundamentals of the simplified procedure. Food Technol. 11:37-43.
Paull, R.E. 1990. Postharvest heat treatments and fruit ripening. Postharvest News \& Info. 1:355363.

Paull, R.E. and N.J. Chen. 1990. Heat shock response in field-grown, ripening papaya fruit. J. Amer. Soc. Hort. Sci. 115:623-631.

Reyes, A.A. and R.B. Smith. 1986. Controlled atmosphere effect on the pathogenicity of fungi on celery and on the growth of Botrytis cinerea. HortScience 21:1167-1169.

Smith, W.L. and J.T. Worthington. 1965. Reduction of postharvest decay of strawberries with chemical and heat treatments. Plant Dis. Rptr. 49:619623.

Spalding, D.H and W.F. Reeder. 1986. Decay and susceptibility of mangoes treated with combinations of hot water, imazalil and radiation. Plant Dis. 70:1149-1151.

Teitel, D.C., Y. Aharoni, and R. Barkai-Golan. 1989. The use of heat treatments to extend the shelf life of 'Galia' melons. J. Hort. Sci. 64:367-372. 